\title{
Informed Consent in Obstetrics and Gynecology: Indian Scenario
}

\section{Anupama Bhute}

\begin{abstract}
Informed consent is the process by which the treating health care provider discloses appropriate information to a competent patient so that the patient may make a voluntary choice to accept or refuse treatment. Or, in simple words, consent is agreement or permission to do or allow something. The element of consent is one of the critical issues in the area of medical treatment today. It is well known that the patient must give valid consent to medical treatment; and it is his or her prerogative to refuse treatment even if the said treatment will save their life. No doubt this raises many ethical debates and falls at the heart of medical law today. This study reviews the various provisions by the Royal College of Obstetricians and Gynaecologists for consent in obstetrics and gynecology as well as the Indian legal provisions in consent.

Keywords: Consent in obstetrics and gynecology, Informed consent, Informed risk consent, Written consent.

How to cite this article: Bhute A. Informed Consent in Obstetrics and Gynecology: Indian Scenario. Int J Recent Surg Med Sci 2017;3(1):67-71.
\end{abstract}

Source of support: Nil

Conflict of interest: None

\section{INTRODUCTION}

Informed consent is the process by which the treating health care provider discloses appropriate information to a competent patient so that the patient may make a voluntary choice to accept or refuse treatment. ${ }^{1}$ In simple words, consent is agreement or permission to do or allow something. The element of consent is one of the critical issues in the area of medical treatment today. It is well known that the patient must give valid consent to medical treatment; and it is his or her prerogative to refuse treatment even if the said treatment will save their life. No doubt this raises many ethical debates and falls at the heart of medical law today.

\section{TYPES OF CONSENT}

- Informed consent

- Expressed consent

Consultant Obstetrician and Gynecologist

Department of Obstetrics and Gynecology, Kidney Centre, Jasleen Hospital; Central India's Child Hospital and Research Institute Jeswani Multispeciality Hospital, Nagpur, Maharashtra, India

Corresponding Author: Anupama Bhute, Consultant Obstetrician and Gynecologist, Department of Obstetrics and Gynecology Kidney centre, Jasleen Hospital; Central India's Child Hospital and Research Institute; Jeswani Multispeciality Hospital, Nagpur Maharashtra, India, e-mail: anupamaa28@gmail.com
- Implied consent

- Surrogate consent

- Advance consent

\section{HISTORY}

The Hippocratic Oath prevalent for centuries has granted doctors the right to decide in the best interest of the patient. The oath advices that physician should conceal most of the information from patients in order to give the best of care. ${ }^{2}$ But the same has conflicted with the trend of 20th-century right of "freedom to control health as well as avoiding non-consensual medical treatment." Henri de Mondeville, a French surgeon in the 1300s, emphasized the need for the patient to have confidence in the doctor. ${ }^{3}$ Benjamin Rush, an 18th-century US physician, advised that doctors ought to share as much information as possible with patients. ${ }^{1}$ Thomas Percival in his book called Medical Ethics, published in 1803, mentioned that patients have a right to truth, but when the physician could provide better treatment by lying or withholding information, he advised that physician should do as they thought best. ${ }^{1}$

The earliest expression of this fundamental principle, based on autonomy, is found in the Nuremberg Code of 1947. ${ }^{4}$ The Nuremberg Code was adopted immediately after World War II in response to medical and experimental atrocities committed by the German Nazi regime. The code makes it mandatory to obtain voluntary and informed consent of human subjects.

The Medical Council of India (MCI) has laid down guidelines that are issued as regulations in which consent is required to be taken in writing before performing an operation. The MCI guidelines are applicable to operations and do not cover the extent of other treatments or procedures. These are covered under implied and expressed consent. ${ }^{5}$

\section{DEFINITION}

It is defined as voluntary acceptance after full understanding, by a competent patient, of a plan for medical care after physician adequately discloses the proposed plan, its risks and benefits, and alternative approaches.

The decision-making capacity is free from coercion or manipulation by the patient/doctor. 


\section{VITAL COMPONENTS OF INFORMED CONSENT}

- Mental capacity of the patient to enter into a contract (this also includes their ability to understand information given);

- Complete information to be provided by doctor;

- Voluntary acceptance of the procedure by the patient or person and the specific procedure .

\section{CONTENTS OF THE CONSENT}

- A description of the recommended treatment or procedure;

- A description of the risks and benefits - particularly exploring the risk of serious bodily disability or death;

- A description of alternative treatments and the risks and benefits of alternatives;

- The probable results if no treatment is undertaken;

- The probability of success and a definition of what the doctor means by success;

- Length and challenges of recuperation; and

- Any other information generally provided to patients in this situation by other qualified physicians.

\section{ELIGIBILITY FOR CONSENT}

- Age (more than 18 years, in case of minor guardian to authorize)

- Soundness of mind

- Ability to understand

- Remember the information given

- Ability to deliberate and decide the treatment choices

- Believes that the information applies to the said patient and specific purpose

\section{PRINCIPLES OF CONSENT}

- Listen to patient and respect their views about their health;

- Discuss with patient about diagnosis, prognosis, treatment, and care involved;

- Share with patients the information they want or need in order to make a decision for themselves;

- Respect patient's decision.

\section{EXPRESSED CONSENT}

\section{Oral Consent}

Oral consent is mainly required in cases where examination of females is required. Tests necessitating removal of body fluids and radiological examination can be done after securing oral consent.

\section{Written Consent}

Consent should be taken in the patient's vernacular language. Written consent is mandatory in every invasive diagnostic/therapeutic procedure or any medicolegal examination.

\section{IMPLIED CONSENT}

It is only for routine examination as well as treatment. This does not extend to the performance of intimate examination or diagnostic procedure.

\section{SURROGATE CONSENT}

Consent given by family members for minors or the dead is a surrogate consent. Generally, courts have held that consent of family members with the written approval of two physicians sufficiently protects a patient's interest.

\section{ADVANCE CONSENT}

It is the consent given by patient in advance before death.

\section{PROXY CONSENT}

It indicates consent given by an authorized person before or after death. If an unconscious patient is brought and an operation is essential to save life, two or three doctors are required to give consent by signing on consent form.

\section{BLANKET CONSENT FORMS}

The worst solution to documenting informed consent is the form that blankets all possibilities. The typical blanket form recites that the physician and his or her designees may do what they think is necessary. These forms usually contain language about how the physician has discussed the treatment with the patient and that the patient has had an opportunity to ask questions. Such a form may protect the physician from a battery of accusations. As the sole records of consent, these forms are worthless.

\section{Clinical Governance Advice \\ No. 6 December 2008}

This guidance provides good practice framework for obtaining valid consent in obstetrics and gynecology. ${ }^{6}$ Specific advice for some individual procedures has been published separately and is available from the Royal College of Obstetricians and Gynaecologists website: www.rcog.org.uk

\section{Pelvic Examination}

It is essential that the gynecologist considers what information will be gained by the examination, whether there is a screening or diagnostic procedure, and whether or not the examination is necessary at that time. Verbal consent should be obtained in the presence of a chaperone who is to be present during the examination. Consent should 
also be specific to whether the intended examination is vaginal, rectal, or both. Communication skills are essential in conducting intimate examination.

\section{Breast Examination}

There is no evidence to support routine breast examination in the pregnant women, nor in the routine gynecological patient. ${ }^{6}$ Should examination of the breast be considered necessary for clinical reasons, verbal consent should be obtained, again in the presence of a chaperone.

\section{Unexpected Pathology}

If the unexpected pathology is minor, then treatment can be performed provided the woman has been made aware of this possibility and has consented to the consequences of a minor treatment. If the unexpected pathology is major, then it is unwise to proceed with any additional surgery without discussing them with the woman, even if this means a second operation. ${ }^{6}$

\section{Unexpected Pregnancy}

All reasonable steps should be taken to exclude pregnancy before embarking upon any surgical procedure. A potential viable pregnancy should not be terminated without the woman's consent. If a pregnancy is discovered at the start of hysterectomy, including one for cancer, the operation should be rescheduled. An unexpected ectopic pregnancy should be removed. It is reasonable to presume that the woman would wish this and would wish the surgeon to act in favor of lifesaving treatment. ${ }^{6}$

\section{Consent by Women in Pain and in Labor}

Women who are pain free in labor by epidural anesthesia can consent normally. Women who are in pain or under the influence of narcotic analgesic cannot give consent normally. Reasonable care needs to be taken while getting consent from them like giving information in between contractions. Consent to be sterilized should not be obtained while a woman is in labor, but an exception to this may be made if the woman has been fully informed during antenatal period. ${ }^{6}$

\section{Consent for Ultrasound Examination}

Clear written advice should be given before ultrasound screening in pregnancy. The advice should indicate the nature and purpose of the examination, together with the detection rate for defined common conditions. Detection rate figures quoted should be from reliable sources, such as robust local or national data. Written consent for ultrasound screening is not currently considered necessary, but women should be given the opportunity to request further information and such a discussion should be clearly documented in the patient record. ${ }^{6}$

\section{Consent for Training}

Explicit consent of women is required for the presence of students:

- During gynecological and obstetric consultation

- In operating theaters as observers and assistants

- Performing clinical pelvic examination

Written consent must be obtained for pelvic examination of anesthetized women. ${ }^{6}$

\section{Consent for obtaining Tissue Sample}

Specific consent for the removal of tissue for histological examination is not required. Women must, however, be made aware that tissue and samples may be removed in the course of the procedure for which consent is being obtained. The advice given to the woman must include the examination of these tissues and the woman should be informed that blocks and slides will be retained while the remaining sample is destroyed. The retained tissue may be used for education and training. Consent must, however, be obtained when tissue is to be used for research purposes, except where the samples are anonymized. ${ }^{6}$

\section{Consent for Publication}

Multimedia images may be part of the patient record. It is important to remember that the woman must consent not only to the image being made but also to the specific use to which it is put. If it is proposed that the image may be used for education or teaching, then written consent must be obtained and the use must not be wider than that to which consent has been given. If the woman will be recognizable from the image, this must be made clear to her before she consents. ${ }^{6}$

\section{Consent for Screening}

A woman is made aware of the purpose, uncertainties, and implications of screening, as well as ensuring that the information she wishes is identified and provided. It should also be considered that the woman may be unaware of the purpose of the 20-week anomaly scan. She should therefore, be informed of the screening purposes of this scan beforehand. ${ }^{6}$

\section{WHEN IS CONSENT NOT REQUIRED?}

Medicolegal cases bought by police consent is implied under Sec. 53 of criminal procedure code; ${ }^{7}$

Consent is not required in medical examination and issue of certificate for insurance policies;

Cases where it is issued in the interest of the community; 
A person suffering from disease under "notified" category;

Prisoners (new entrants);

Examination under Court Order;

Request by a police officer under Cr.P.C. Section 53.

\section{Legal Principles of Informed Consent}

Section 10 of the Indian Contract Act 1872 says that "all agreements are contracts if they are made by the free consent of parties competent to contract, for a lawful consideration and with a lawful object, and are not hereby expressly declared to be void." Section 10 also provides that unless law requires, such contract need not be registered or need not be in writing. This is the legal position of consent and contract in the Law of the Contract.

Consent is said to be free when it is not caused by coercion, undue influence, fraud, misinterpretation, or mistake. The consent must be to do a lawful act and it must not disobey any provision of the law. Consent by intoxicated person, person of unsound mind, or a person below 12 years of age is invalid [Section 90 IPC (Indian Penal Code)]. According to Section 90 IPC, a child less than 12 years of age or insane person cannot give valid consent. By implication from Section 90 IPC, one can say that in general, a boy or girl can consent to medical or surgical treatment if he or she is above 12 years of age provided the treatment is intended for his or her benefit and is undertaken in good faith. ${ }^{7}$

Sections 88 and 90 of the IPC suggest that the age for giving valid consent for any medical procedure is 12 years. Hence, a doctor taking consent for medical or surgical treatment from a person aged 12 years or more can be legally said to have taken a valid consent and cannot be held criminally liable on this account.

However, Section 87 IPC mentions 18 years as the age for giving consent for acts not intended and not known to be likely to cause death or grievous hurt. These acts are not necessarily for the benefit of the person. Hence, Section 87 IPC is not applicable to the medical profession as here (in Section 87 IPC), the acts are NOT done for the person's benefit.

Oral consent is legally valid when taken for some specific procedures, like injecting medication, drawing blood for pathological examination, gynecological examinations, etc. Oral consent can be proved in court if it was taken in the presence of witnesses or if the doctor records in the case record of the patient that oral consent was taken. For major procedures and surgery, written consent should be taken but if for some reason only oral consent is possible, then the doctor should enter it in the case record of the patient.

In medical emergencies, consent need not be obtained if circumstances are such that it is impossible for that person to give consent (Section 92 IPC).

\section{In loco parentis}

In an emergency involving children when their parents or guardians are not available, consent is taken from the person in charge of the child, e.g., school teacher.

According to the Indian Medical Council (Professional Conduct and Ethics) Regulations 2002, before performing an operation written consent should be obtained. Those doctors who take consent for legal contracts between two parties feel that both the doctor and patient should sign the consent form as this is the basic requirement of a contract, otherwise it becomes null and void. Two witnesses who are uninterested third parties should preferably also sign it. The consent form also requires the form to be countersigned by the treating doctor who certifies that informed consent has been taken. Consent should be individual and procedure-specific. It should be taken before the procedure as blanket consents are not acceptable.

\section{Facts about Disclosure}

Full disclosure must be there for consent to be legally valid. Exceptions to disclosure requirements are:

- Emergencies: When the time required for disclosure would create a substantial risk of harm to the patient or third parties, full disclosure requirements may not apply.

- Waiver: Patients may waive their rights to receive information. This should be a knowledgeable waiver, i.e., patients should be made aware that they have a right to receive the information, to designate a surrogate to receive the information, or to be informed at a later date.

- Therapeutic privilege: Information can be withheld, when disclosure per se would be likely to cause harm to patients (e.g., when a patient with an unstable cardiac arrhythmia would have his or her situation exacerbated by the anxiety attendant on full disclosure of the risk of treatment). In emotionally disturbed patients, the doctor should request a specialist consultation to establish that the patient is emotionally disturbed. The doctor should also note their decision in the patient's records explaining their intentions and the reasons for it.

- Incompetence: Incompetent patients may not, as a matter of law, give an informed consent. State law generally provides alternative mechanisms by which consent can be obtained, and requires disclosure to a substitute decision-maker.

- Involuntary treatment: Many states allow psychiatric treatment to occur without patients' informed consent. This occurs most commonly when patients' refusals of treatment is specifically overridden following clinical, administrative, or judicial review. 


\section{TAKE-HOME MESSAGE}

Careful documentation, ongoing education, and provision of opportunities for collaborative decision-making in such cases may be more effective and can provide effective legal protection.

\section{REFERENCES}

1. Appelbaum PS. Clinical practice. Assessment of patients' competence to consent to treatment. N Engl J Med 2007 Nov;357(18):1834-1840.

2. Faden, RR.; Beauchamp, TL.; King, NMP. A history and theory of informed consent. Online ed. New York: Oxford University Press; 1986.
3. Burns, CR. Legacies in ethics and medicine. New York: Science History Publications; 1977. ISBN 9780882021669.

4. Annas, GJ.; Michael, AG. The Nazi doctors and the Nuremberg Code. New York: Oxford University Press Inc.; 1992.

5. Code of Ethics Regulations. Published in Part III, Section 4 of the Gazette of India; 2002 Apr 6.

6. Obtaining Valid Consent (Clinical Governance Advice No. 6) RCOG Published; 2015 Jan 28.

7. Kohli A. Medical consent in India - ethical and legal issues. Anil Aggrawal's Internet J Forensic Med Toxicol [serial online] 2007 Jul-Dec; [cited 2007 Jul 1];8(2):[about 19 p]. Available from: http://www.anilaggrawal.com/ij/vol_008_ no_002/papers/paper004.html. 
